\title{
PHẪU THUẬT NỘI SOI TOÀN BỘ, TIM ĐẬP, KHÔNG ROBOT HỖ TRỢ SỬA THÔNG LIÊN NHĨ THỂ XOANG TĨNH MẠCH
}

\author{
Đặng Quang Huy*, Trần Đắc Đại*, Ngô Thị Hải Linh*, Lê Ngọc Thành*
}

\section{TÓM TẮT}

Thông liên nhĩ (TLN) thể xoang tĩnh mạch (TM) là bệnh tim bẩm sinh (TBS) phức tạp. Mặc dù phẫu thuật là lựa chọn duy nhất, người bệnh vẫn phải đối mặt với nhiều nguy cơ sau mổ, như: hẹp tĩnh mạch chủ (TMC) trên hoặc các tĩnh mạch phổi (TMP), tồn lưu và suy chức năng nút xoang. Chưa có một báo cáo nào về ứng dụng phẫu thuật nội soi toàn bộ (NSTB) tim đập trong điều trị bệnh này. Chúng tôi báo cáo trường hợp bệnh nhân nam 28 tuổi, chẩn đoán TLN thể xoang tĩnh mạch, được phẫu thuật thành công bằng phương pháp nội soi toàn bộ, tim đập, không robot hỗ trợ với kỹ thuật một miếng vá.

Từ khóa: Thông liên nhĩ thể xoang tĩnh mach, tĩnh mach phổi lạc chỗ, phẫu thuật tim it xâm lấn, phẫu thuật nội soi toàn bộ.

\section{MỞ ĐẦU}

Thông liên nhĩ (TLN) thể xoang TM được định nghĩa là những lỗ thông nằm ngay dưới chân TMC trên, kèm theo TMP trên phải đổ về TMC trên hoặc chỗ nối TMC trên - nhĩ phải (NP). Đây là bệnh TBS không thường gặp, chiếm $4-10 \%$ trong các bệnh nhân TLN.[1] Do đặc điểm về tương quan giải phẫu giữa các thương tổn, người bệnh phải đối mặt với nhiều nguy cơ sau mổ, như: hẹp TMC trên hoặc TMP, tồn lưu và đặc biệt là suy chức năng nút xoang. [2,3] Theo hiểu biết của chúng tôi, Lewis cùng cộng sự là người đầu tiên và duy nhất cho tới tới thời điểm này công bố áp dụng thành công phẫu thuật NSTB có robot hỗ trợ trong điều trị TLN thể xoang TM. [4] Trong bài này, chúng tôi mô tả một trường hợp TLN thể xoang TM được phẫu thuật thành công bằng phương pháp NSTB, tim đập, không robot hỗ trợ với kỹ thuật một miếng vá.

\section{TRƯờNG HỢP BÊ̂NH}

Bệnh nhân (BN) nam 29 tuổi, không có triệu chứng lâm sàng, được chẩn đoán TLN khi khám sức khỏe định kỳ. Siêu âm (SA) tim qua thành ngực xác định lỗ $\mathrm{TLN}$ nằm ngay dưới chân TMC trên, đk $23 \mathrm{~mm}$, shunt T-P hoàn toàn; TMP trên phải đổ ngay chố nối TMC trên - $\mathrm{NP}$; đường kính thất phải là $40 \mathrm{~mm}$, van ba lá hở nhẹ, chênh áp qua VBL là $45 \mathrm{mmHg}$. Thông tim cho thấy mạch vành bình thường, tỉ lệ lưu lượng tuần hoàn phổi - hệ thống $(\mathrm{Qp} / \mathrm{Qs})$ là 2.4:1. SA tim qua thực quản giúp xác định chẩn đoán. Động mạch chủ (ĐMC) bụng và động mạch chậu, đùi có kích thước bình thường, không xơ vữa trên $\mathrm{SA}$ doppler mạch trước mổ.

\subsection{Kỹ thuật mổ}

$\mathrm{BN}$ được đặt ở tư thế nằm ngửa với phần bên phải cơ thể được nâng cao $30^{\circ}$, hai tay dọc theo thân người, gây mê thông thường với nội khí quản một nòng. Tuần hoàn ngoài cơ thể ngoại vi được thiết lập với ống thông động mạch đùi được đặt gián tiếp qua đoạn mạch Dacron số 8; trong khi đó ống thông TMC trên và $\mathrm{TMC}$ dưới được đặt qua $\mathrm{TM}$ cảnh trong và TM đùi theo phương pháp Seldinger. Bốn trocar được thiết lập trên ngực phải của $\mathrm{BN}$, bao gồm: 01 trocar $12 \mathrm{~mm}$ tại khoang liên sườn (KLS) 5 đường nách trước cho tay làm việc chính, 01 trocar $5 \mathrm{~mm}$ tại KLS 4 đường nách giữa cho tay làm việc phụ, 01 trocar $5 \mathrm{~mm}$ tại KLS 5 đường nách giữa cho camera và 01 trocar $5 \mathrm{~mm}$ tại KLS 6 đường nách giữa cho đường hút máu về.

\footnotetext{
* Trung tâm Tim mạch Bệnh viện E

Ngườ chịu trách nhiệm khoa học: GS.TS. Lê Ngoc Thành

Ngày nhận bài: 01/04/2018 - Ngày Cho Phép Đăng: 10/04/2018

Phản Biện Khoa học: GS.TS. Bùi Đúc Phú PGS.TS. Đặng Ngọc Hùng
} 


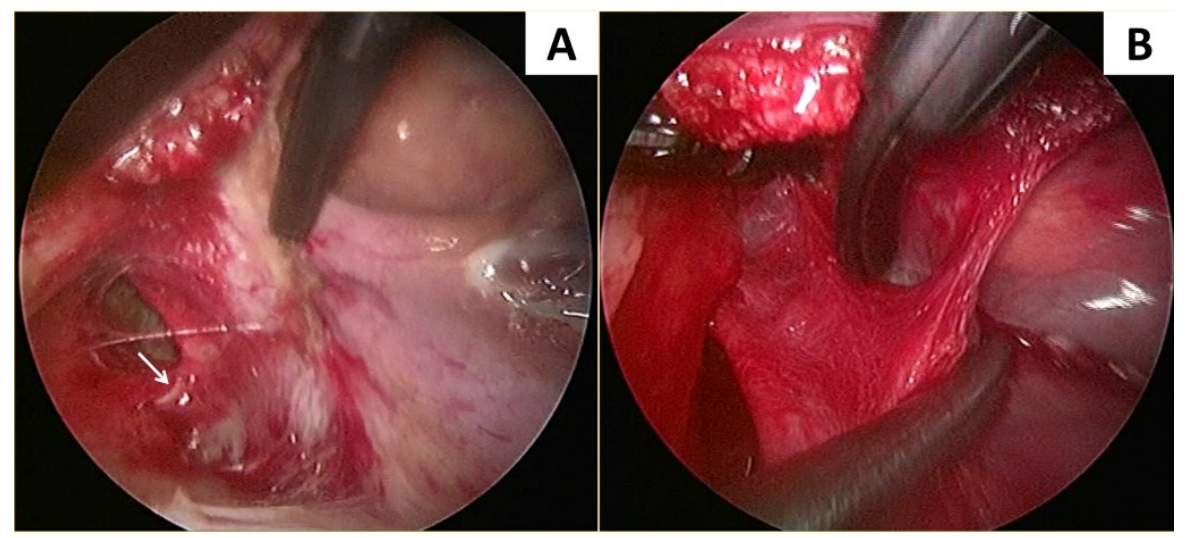

Hình 2.1. Thương tổn nhìn từ mặt ngoài tim. A, Phần ngoài màng tim của $T M C$ trên. TMP trên phải (mũi tên trắng) chạy từ sau ra trước và từ ngoài vào trong đổ vào $\mathrm{TMC}$ trên tại chỗ nối $\mathrm{TMC}$ trên $-\mathrm{NP}$. B, TMC trên tiếp tục được phẫu tích lên cao, trên chỗ nối TMC trên - NP $3-4 \mathrm{~cm}$.

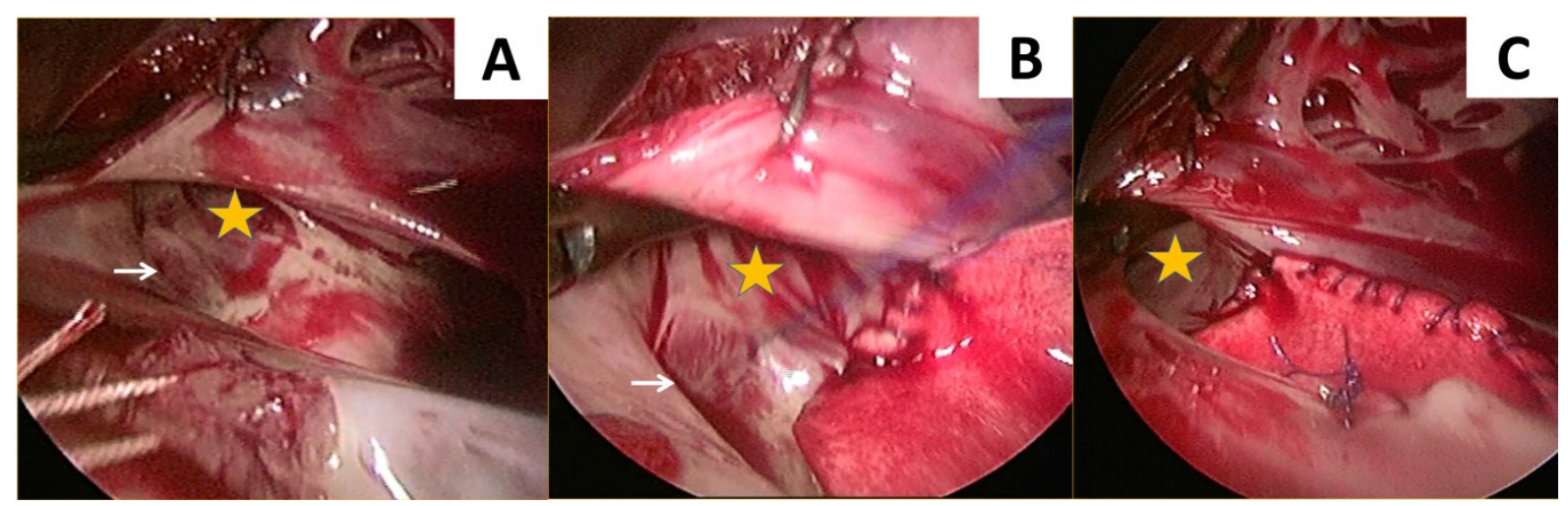

Hình 2.2. Tổn thương nhìn từ mặt trong NP và quá trình sửa chữa. $\mathbf{A}$, Thành $\mathrm{NP}$ được khâu treo vào màng tim giúp bộc lộ rõ tổn thương trong tim: lỗ TLN kiểu lỗ thứ hai lớn, không còn gờ TMC trên. TMP trên phải (mũi tên trắng) nối tiếp với TMC trên (ngôi sao vàng) ở vị trí hơi cao một chút so với chỗ nối TMC trên - NP. B, Miếng vá nhân tạo được sử dụng để vá lỗ TLN và tạo vách ngăn cách giữa $\mathrm{TMC}$ trên và $\mathrm{TMP}$ trên phải. $\mathrm{C}, \mathrm{Kiểm} \mathrm{tra} \mathrm{sau} \mathrm{khi} \mathrm{hoàn} \mathrm{thành} \mathrm{miếng} \mathrm{vá,} \mathrm{lỗ} \mathrm{đổ} \mathrm{của} \mathrm{TMC} \mathrm{trên} \mathrm{thông}$ thoáng, miếng vá không bị trùng

Màng tim được mở song song và cách thành trước ngực khoảng $2 \mathrm{~cm}$. Màng tim được khâu treo vào cơ hoành và khâu kéo qua chân trocar để bộc lộ phẫu trường. TMP trên phải chạy theo hướng từ sau ra trước và từ ngoài vào trong để đổ vào ngay trên chỗ nối TMC trên - NP (Hình 1A). TMC trên được phẫu tích cao trên chỗ nối TMC trên - NP khoảng 3-4cm (Hình 1B). Do khó thắt TMC trên, chúng tôi cặp TMC trên ở vị trí cao nhất đã phẫu tích bằng clamp Chitwood (đặt qua thành ngực). TMC dưới để tự do, tim đập liên tục trong suốt quá trình mổ.
Nhịp xoang và tần số tim được theo dõi liên tục trong suốt quá trình mổ.

BN được đặt ở tư thế Trendelenberg. NP được mở song song và cách rãnh nhĩ - thất $1.5 \mathrm{~cm}$, hướng về phía TMC trên; đầu trên của đường mở nhĩ tới cách chỗ nối TMC trên $-\mathrm{NP} 1 \mathrm{~cm}$. Các mép của NP được khâu treo vào màng tim để bộc lộ các cấu trúc trong NP (Hình $2 \mathrm{~A}$ ).

\subsection{Ngăn ngù̀a khí từ thất trái vào $Đ M C$}

Khoang màng tim và màng phổi được làm đầy bởi $\mathrm{CO} 2$. Ban đầu $\mathrm{CO} 2$ được bơm với tốc độ $0,51 /$ phút, sau đó tốc độ bơm sẽ được điều 
chỉnh để duy trì áp lực riêng phần của $\mathrm{CO} 2$ trong máu động mạch trong khoảng 35$40 \mathrm{mmHg}$. Áp lực đường động mạch được duy trì $>60 \mathrm{mmHg}$ trong suốt quá trình mổ.

\subsection{Ngăn ngừa khí về TMC dưới và vào đường động mạch}

Cannula TMC dưới được đặt sao cho đầu cannula nằm dưới van Eustachian $1-2 \mathrm{~cm}$ để ngăn khí về TMC dưới. Phổi $\mathrm{FX}$ của hãng Terumo (CAPIOX FX Advance Oxygenator, Terumo, Bangkok, Thailand) được sử dụng để ngăn khí từ bình chứa vào đường động mạch.

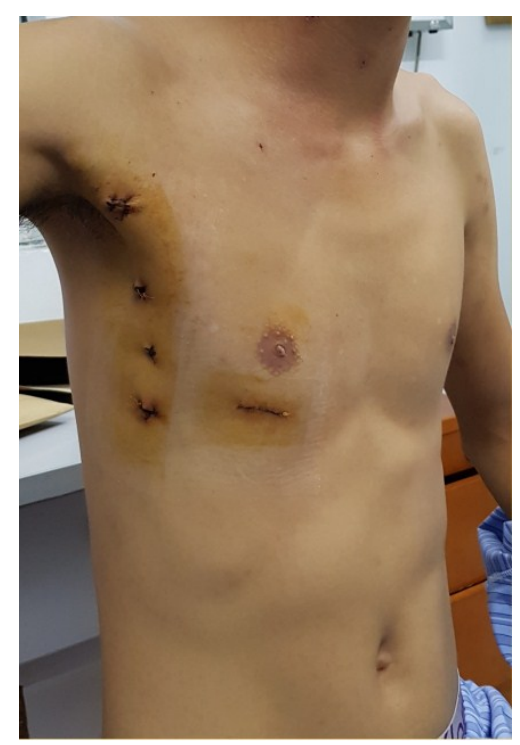

Hinh 3. Sẹo mổ của BN truớc khi ra viện.

Sau khi đánh giá vị trí kích thước lỗ TLN cũng như mối tương quan giải phẫu giữa $\mathrm{TMC}$ trên và lỗ TMP trên phải, một miếng vá nhân tạo được sử dụng để vá lỗ TLN đồng thời tạo vách ngăn chia tách lỗ TMC trên và lỗ TMP trên phải (Hình 2B). Ngay trước khi hoàn thành đường khâu, bác sĩ gây mê bóp bóng làm nở phổi giúp đẩy khí ra khỏi nhĩ trái. Những tiêu chuẩn thành công trong mổ bao gồm: (1) đường khâu kín, (2) miếng vá không bị trùng và (3) lỗ TMC thông thoáng (Hình $2 \mathrm{C}$ ). NP được đóng 2 lớp, khâu vắt. Ngừng tuần hoàn ngoài cơ thể và kết thúc cuộc mổ không gặp khó khăn gì. Thời gian mổ và thời gian chạy máy lần lượt là 220 phút và 120 phút. Bệnh nhân nằm hồi sức sau mổ 18 giờ, ra viện sau 6 ngày không có biến chứng về thần kinh và mạch máu. Kết quả SA trước khi ra viện: vách liên nhĩ kín, lỗ TMC trên và lỗ TMP trên phải thông thoáng. Điện tâm đồ sau mổ cho thấy nhịp xoang, tần số $72 \mathrm{Ck} /$ phút. $\mathrm{SA}$ và điện tâm đồ khi khám lại sau 3 tháng không phát hiện bất thường. $\mathrm{BN}$ và gia đình rất hài lòng với với tính thẩm mỹ của sẹo mổ (Hình 3).

\section{BÀN LUẬN}

Phẫu thuật NSTB có hoặc không có robot hỗ trợ đã được ứng dụng trong điều trị bệnh TLN đơn thuần từ đầu những năm 2000. Mặc dù hầu hết tác giả bảo vệ cơ tim bằng liệt tim xuôi dòng có cặp ĐMC và đuổi khí bằng kim gốc $\mathrm{ĐMC}$; một vài tác giả đã sử dụng phương pháp đuổi khí bằng $\mathrm{CO} 2$ để áp dụng phẫu thuật tim đập,[5] thậm chí không sử dụng kim gốc ĐMC.[6]

Phẫu thuật điều trị TLN thể xoang TM là một phẫu thuật có nhiều nguy cơ với tỉ lệ 4-7\% trường hợp hẹp lỗ đổ của TMC trên,[3] 2-4\% trường hợp hẹp lỗ đổ của TMP trên phải,[3] và từ $6,5-55 \%$ trường hợp suy nút xoang sau mổ tùy theo từng kỹ thuật.[2] Với kinh nghiệm hơn 100 trường hợp phẫu thuật NSTB không robot hỗ trợ trong điều trị TLN đơn thuần tim 
đập, thông liên thất, thông sàn nhĩ thất bán phần, u nhầy nhĩ trái, màng ngăn nhĩ trái; chúng tôi đã phẫu thuật thành công ca bệnh trong báo cáo này. Theo hiểu biết của chúng tôi, đây là báo cáo thứ 2 về phẫu thuật NSTB trong điều trị TLN thể xoang TM sau Lewis cùng cộng sự.[4] $\mathrm{Ca}$ bệnh này cho thấy rằng không chỉ TLN đơn thuần, nhiều bệnh TBS phức tạp đã có thể được sửa chữa thành công bằng phẫu thuật NSTB.

\section{TÀI LIỆ THAM KHẢO}

1. Attenhofer Jost CH, Connolly HM, Danielson GK, et al. Sinus venosus atrial septal defect: long-term postoperative outcome for 115 patients. Circulation. 2005;112(13):1953-1958.

2. Okonta KE, Agarwal V. Does Warden's procedure reduce sinus node dysfunction after surgery for partial anomalous pulmonary venous connection? Interactive cardiovascular and thoracic surgery. 2012;14(6):839-842.
3. Okonta KE, Tamatey M. Is double or single patch for sinus venosus atrial septal defect repair the better option in prevention of postoperative venous obstruction? Interactive cardiovascular and thoracic surgery. 2012;15(5):900-903.

4. Lewis CT, Bethencourt DM, Stephens RL, et al. Robotic repair of sinus venosus atrial septal defect with partial anomalous pulmonary venous return and persistent left superior vena cava. Innovations (Philadelphia, Pa). 2014;9(5):388-390.

5. Ma ZS, Dong MF, Yin QY, et al. Totally thoracoscopic closure for atrial septal defect on perfused beating hearts. European journal of cardio-thoracic surgery : official journal of the European Association for Cardiothoracic Surgery. 2012;41(6):1316-1319.

6. Gao C, Yang M, Wang $G$, et al. Totally endoscopic robotic atrial septal defect repair on the beating heart. The heart surgery forum. 2010;13(3): E155-158. 